\title{
O CUMPRIMENTO DE SENTENÇA CONTRA A FAZENDA PÚBLICA NO NCPC
}

\author{
Vanessa Inhasz Cardoso
}

\section{INTRODUÇÃO}

O Novo Código de Processo Civil (NCPC), de 2015, estabeleceu significativas modificações em relação ao Código de Processo Civil de 1973 (CPC/73) no que se refere à execução contra a Fazenda Pública, sendo essencial a análise de tais alterações, especialmente no que se refere ao cumprimento de sentença contra a Fazenda Pública, para que se possam aplicar as novas regras de forma correta, garantindo a satisfação do direito do credor.

No CPC/73, a execução se realizava sempre por meio de processo autônomo, havendo citação da Fazenda Pública para opor embargos à execução no prazo de 10 dias, nos casos de título executivo judicial ou extrajudicial. Diferentemente, no NCPC os títulos executivos judiciais constituídos devem ser cobrados de acordo com a modalidade de cumprimento de sentença (art. 534 e 535), instaurada nos próprios autos, ou seja, independentemente da instauração de processo autônomo, os títulos executivos extrajudiciais devem seguir o rito do processo de execução, previsto no art. 910 do NCPC, com processo autônomo. Em ambos os casos, o prazo para apresentação de defesa é de 30 dias, sendo que o instrumento cabível no cumprimento de sentença é a impugnação e na execução contra a Fazenda Pública são os embargos à execução.

Discorreremos sobre os requisitos para instauração do procedimento de cumprimento de sentença, as matérias a serem alegadas em sede de impugnação, a forma de pagamento dos créditos e as consequências da falta de defesa, sempre 
comparando e ressaltando os aspectos aplicáveis à execução de sentença, bem como salientando as diferenças com relação ao CPC/73.

A metodologia utilizada é análise da legislação, mais precisamente os art. 534, 535 e 910 do NCPC e os artigos que dispõem sobre a execução contra a Fazenda Pública no CPC/73 (especialmente o art. 730 e seguintes), bem como os comentários da doutrina sobre os referidos dispositivos, realizando uma análise crítica e comparada das alterações.

\section{CUMPRIMENTO DE SENTENÇA CONTRA A FAZENDA PÚBLICA}

Como mencionado no tópico anterior, o CPC/73 (art. 730 e 731) previa um procedimento único para a execução contra a Fazenda Pública, que contemplava tanto os títulos judiciais quanto os extrajudiciais. O NCPC, contudo, segregou em dois os ritos de execução de créditos contra a Fazenda Pública com base na natureza dos títulos a serem executados - títulos judicial e extrajudicial.

A execução fundada em título executivo judicial deve seguir o rito do cumprimento de sentença contra a Fazenda Pública, previsto nos art. 534 e 535 do NCPC. No caso de título extrajudicial, o rito a ser observado é o de execução contra a Fazenda Pública, regulamentado pelo art. 910 do NCPC. Dessa forma, o NCPC estabeleceu um procedimento próprio denominado cumprimento de sentença contra a Fazenda Pública. A nomenclatura execução contra a Fazenda Pública ficou destinada exclusivamente à execução fundada em título extrajudicial.

Além da segregação dos ritos, o NCPC trouxe uma alteração relevante ao dispor que o cumprimento de sentença contra a Fazenda Pública (títulos executivos judiciais) será instaurado nos mesmos autos do processo em que foi proferida a sentença condenatória, não sendo mais necessária a instauração de processo autônomo, tornando a execução uma fase do procedimento subsequente à fase de conhecimento. A não instauração de processo autônomo para o cumprimento de sentença está em total consonância com os princípios de celeridade e eficiência processual norteadores do NCPC, com as alterações introduzidas visando essencialmente à satisfação do direito do credor de forma mais ágil.

Feitos esses esclarecimentos iniciais, passaremos a tratar do rito de cumprimento de sentença contra a Fazenda Pública. 


\subsection{Procedimento para instauração do cumprimento de sentença}

O cumprimento de sentença de título judicial está previsto nos art. 534 e 535 do NCPC e será instaurado nos mesmos autos do processo principal. Nos termos do art. 534, o cumprimento de sentença é iniciado pela apresentação de demonstrativo discriminado e atualizado do crédito exequendo, a saber:

Art. 534. No cumprimento de sentença que impuser à Fazenda Pública o dever de pagar quantia certa, o exequente apresentará demonstrativo discriminado e atualizado do crédito contendo:

I - o nome completo e o número de inscrição no Cadastro de Pessoas Físicas ou no Cadastro Nacional da Pessoa Jurídica do exequente;

II - o índice de correção monetária adotado;

III - os juros aplicados e as respectivas taxas;

IV - o termo inicial e o termo final dos juros e da correção monetária utilizados;

$\mathrm{V}$ - a periodicidade da capitalização dos juros, se for o caso;

VI - a especificação dos eventuais descontos obrigatórios realizados.”

$\llbracket 1^{\circ}$ Havendo pluralidade de exequentes, cada um deverá apresentar o seu próprio demonstrativo, aplicando-se à hipótese, se for o caso, o disposto nos $\int \mathbb{S} 1^{\circ}$ e $2^{\circ}$ do art. 113 .

$\llbracket 2^{\circ} \mathrm{A}$ multa prevista no $₫ 1$ o do art. 523 não se aplica à Fazenda Pública.

Conforme se depreende do caput e dos incisos do artigo transcrito, que replica o disposto no art. 524 do NCPC (Capítulo III - Do cumprimento definitivo da sentença que reconhece a exigibilidade da obrigação de pagar quantia certa), é obrigação do exequente/credor a apresentação do demonstrativo discriminado e atualizado do crédito.

$\mathrm{O} \int 1^{\circ}$ dispõe que, caso haja pluralidade de exequentes, cada um deverá apresentar o seu próprio demonstrativo, sem prejuízo da possibilidade de limitação ao litisconsórcio multitudinário (art. 113, $\iint 1^{\circ}$ e $2^{\circ}, \mathrm{NCPC}$ ), com o fim de prestigiar os princípios preconizados pela novel legislação de razoável duração do processo, proteção ao contraditório e ampla defesa. O referido demonstrativo detalhado do crédito exequendo é requisito obrigatório do requerimento do credor, sendo que, se um dos itens não for observado, o juiz poderá requerer que a parte saneie a irregularidade ou, caso o demonstrativo esteja muito incompleto 
e não contemple a maioria dos itens acima, indeferir o requerimento de cumprimento de sentença.

A elaboração de tal demonstrativo pode se mostrar tarefa complexa dependendo do tipo de crédito a ser executado, o que pode demandar a contratação de profissionais habilitados. Nesse sentido são os comentários de Wambier, Didier, Talamini e Dantas, ${ }^{1}$ a saber:

A memória de cálculo de atualização e incidência de consecutários é, portanto, requisito do requerimento do credor, sem o qual poderá ser indeferido o início do procedimento de cumprimento de sentença. Tal exigência poderá se tornar um obstáculo aqueles credores que possuam crédito que dependam de cálculos de atualização que apesar de meramente aritméticos, sejam complexos e, por conseguinte, devam ser realizados por profissionais habilitados.

É importante ressaltar que, a despeito de o dispositivo em tela claramente estabelecer que a obrigação de apresentar o discriminativo do crédito exequendo é do credor, nada impede que o devedor apresente o cálculo dos valores que entende devidos. Contudo, frise-se, o mencionado procedimento de execução é uma faculdade do executado.

\subsection{Impugnação ao cumprimento de sentença}

Uma vez apresentado o referido demonstrativo de cálculo, a Fazenda Pública será intimada (e não mais citada, como era previsto no $\mathrm{CPC} / 73$ ) na pessoa de seu representante para, querendo, apresentar impugnação (e não mais embargos) nos próprios autos no prazo de 30 dias úteis. ${ }^{2}$ As matérias que podem ser objeto da impugnação estão previstas no art. 535 do NCPC, a saber:

Art. 535. A Fazenda Pública será intimada na pessoa de seu representante judicial, por carga, remessa ou meio eletrônico, para, querendo, no prazo de 30 (trinta) dias e nos próprios autos, impugnar a execução, podendo arguir:

1 WAMBIER, Teresa Arruda Alvim; DIDIER JR., Fredie; TALAMINI, Eduardo; DANTAS, Bruno. Breves comentários ao Novo Código de Processo Civil, de acordo com as alterações da Lei $n^{\circ}$. 13.256/2016. 2. ed. São Paulo: Revista dos Tribunais, 2016. p. 1464.

2 O prazo em questão segue a mesma sistemática de contagem em dias úteis prevista no art. 219 do NCPC. 
I - falta ou nulidade da citação se, na fase de conhecimento, o processo correu à revelia;

II - ilegitimidade de parte;

III - inexequibilidade do título ou inexigibilidade da obrigação;

IV - excesso de execução ou cumulação indevida de execuções;

V - incompetência absoluta ou relativa do juízo da execução;

VI - qualquer causa modificativa ou extintiva da obrigação, como pagamento, novação, compensação, transação ou prescrição, desde que supervenientes ao trânsito em julgado da sentença.

$\int 1^{\circ} \mathrm{A}$ alegação de impedimento ou suspeição observará o disposto nos arts. 146 e 148.

$\int 2^{\circ}$ Quando se alegar que o exequente, em excesso de execução, pleiteia quantia superior à resultante do título, cumprirá à executada declarar de imediato o valor que entende correto, sob pena de não conhecimento da arguição.

$\$ 3^{\circ} \mathrm{Não}$ impugnada a execução ou rejeitadas as arguições da executada:

I - expedir-se-á, por intermédio do presidente do tribunal competente, precatório em favor do exequente, observando-se o disposto na Constituição Federal;

II - por ordem do juiz, dirigida à autoridade na pessoa de quem o ente público foi citado para o processo, o pagamento de obrigação de pequeno valor será realizado no prazo de 2 (dois) meses contado da entrega da requisição, mediante depósito na agência de banco oficial mais próxima da residência do exequente.

$\int 4^{\circ}$ Tratando-se de impugnação parcial, a parte não questionada pela executada será, desde logo, objeto de cumprimento.

$\int 5^{\circ}$ Para efeito do disposto no inciso III do caput deste artigo, considera-se também inexigível a obrigação reconhecida em título executivo judicial fundado em lei ou ato normativo considerado inconstitucional pelo Supremo Tribunal Federal, ou fundado em aplicação ou interpretação da lei ou do ato normativo tido pelo Supremo Tribunal Federal como incompatível com a Constituição Federal, em controle de constitucionalidade concentrado ou difuso.

$\int 6^{\circ}$ No caso do $\int 5^{\circ}$, os efeitos da decisão do Supremo Tribunal Federal poderão ser modulados no tempo, de modo a favorecer a segurança jurídica. 
$\int 7^{\circ} \mathrm{A}$ decisão do Supremo Tribunal Federal referida no $\int 5^{\circ}$ deve ter sido proferida antes do trânsito em julgado da decisão exequenda.

$\int 8^{\circ} \mathrm{Se}$ a decisão referida no $\int 5^{\circ}$ for proferida após o trânsito em julgado da decisão exequenda, caberá ação rescisória, cujo prazo será contado do trânsito em julgado da decisão proferida pelo Supremo Tribunal Federal.

$\mathrm{O}$ artigo traz as mesmas disposições do art. 525, $\mathbb{2} 2^{\circ}$, do NCPC. Comparando as teses passíveis de arguição pela Fazenda Pública com aquelas previstas no art. 525, exclui-se apenas a penhora incorreta ou avaliação errônea, prevista no inciso IV do referido dispositivo.

É importante ressaltar, conforme previsão do $₫ 2^{\circ}$ citado, que, no caso de alegação de excesso de execução, a Fazenda Pública deve de imediato informar o valor que entende correto, sob pena de não conhecimento da arguição. Tal dispositivo prestigia princípios orientadores do NCPC - celeridade processual e duração razoável do processo -, desestimulando as defesas meramente protelatórias que visam apenas atrasar o pagamento do crédito reconhecido em sentença condenatória. Frise-se que tal alegação também é objeto de embargos à execução (art. 917, inciso III, NCPC), devendo também nesse caso ser indicado exatamente em que consiste o excesso.

Sob a égide do CPC/73, o $₫ 5^{\circ}$ do art. 739-A (Título dos Embargos do Devedor) - alterado pela Lei n. 11.382/2006, que introduziu a exigência de indicação do quantum devido quando os embargos forem fundamentados em excesso de execução - não estendeu tal obrigação aos embargos à execução contra a Fazenda Pública. Desde então, surgiu a discussão sobre a (in)aplicabilidade da exigência de indicação, na inicial, do valor devido nos embargos opostos pela Fazenda Pública, com fundamento em excesso de execução. ${ }^{3}$

No julgamento do Recurso Especial (REsp) n. 1.387.248-SC, de relatoria do Ministro Paulo de Tarso Sanseverino, julgado em 7 de maio de 2014 sob o rito dos recursos repetitivos, o Superior Tribunal de Justiça (STJ) posicionou-se no sentido de que a exigência de indicação do valor reputado como correto não alcançava a Fazenda Pública quando alegado excesso de execução em sede de embargos

3 NUNES, Jorge Amaury Maia; NÓBREGA, Guilherme Pupe. Processo e procedimento: notas sobre a execução contra a Fazenda Pública. 2016. Disponivel em: <http://www.migalhas.com.br/ProcessoeProcedimento/106,MI241130,11049-Notas+sobre+a+execucao+contra+a+Fazenda+Publica>. Acesso em: 5 out. 2016. 
à execução. No NCPC, contudo, há previsão expressa tanto no $\ 2^{\circ}$ do art. 535 quanto no $\int 3^{\circ}$ do art. 910 para que a Fazenda Pública declare de imediato o valor que entende correto na impugnação ou em embargos à execução fundados em excesso de execução.

Ademais, a alegação de inexigibilidade do crédito exequendo, prevista no inciso III do caput do mencionado art. 535, pode ser fundada em lei ou ato normativo considerado inconstitucional pelo Supremo Tribunal Federal (STF), em controle de constitucionalidade concentrado ou difuso, antes do trânsito em julgado da decisão exequenda.

Por outro lado, no que se refere à execução fundada em título extrajudicial prevista no art. 910 do NCPC, a Fazenda Pública será citada (em vez de intimada) para, também no prazo de 30 dias, opor embargos à execução, nos quais poderá alegar "qualquer matéria que lhe seria lícito deduzir como defesa no processo de conhecimento". Os embargos serão distribuídos por dependência ao juízo da execução e autuados em separado (art. 914, \ $1^{\circ}$, NCPC), devendo ser instruídos com as cópias processuais relevantes. No mais, a execução fundada em título extrajudicial é regulada pelas mesmas regras aplicáveis ao cumprimento de sentença contra a Fazenda Pública.

Caso a execução não seja impugnada/embargada ou as alegações da Fazenda Pública sejam rejeitadas, será determinada a expedição de precatório ou requisição de pequeno valor (RPV), a depender do valor do crédito. O \ $3^{\circ}$ do art. 535 está em harmonia com a Constituição ao tratar expressamente de tais formas de pagamento. ${ }^{4}$ Nesse aspecto, é importante analisar a questão dos honorários em execução não impugnada pela Fazenda Pública.

\section{HONORÁRIOS EM CUMPRIMENTO DE SENTENÇA NÃO IMPUGNADA PELA FAZENDA PÚBLICA}

$\mathrm{O}$ art. $85, \int 7^{\circ}$, do NCPC prevê que: "Não serão devidos honorários no cumprimento de sentença contra a Fazenda Pública que enseje expedição de precatório, desde que não tenha sido impugnada". O referido dispositivo consolida e expressa o posicionamento defendido no julgamento do Recurso Extraordinário (RE) n. 420.186. O STF adotou interpretação conforme a Constituição para declarar a constitucionalidade do art. $1^{\circ}$-D da Lei n. 9.494/1997, afastando, entretanto,

4 BUENO, Cassio Scarpinella. Novo Código de Processo Civil anotado. São Paulo: Saraiva, 2015. 
a inaplicabilidade de honorários em execução não embargada quando o débito exequendo enquadrar-se nas requisições de pequeno valor. ${ }^{5}$

O racional utilizado pelo legislador na redação do art. 1 $^{\circ}$-D da Lei n. 9.494/1997 foi a ausência de causalidade. Isso porque a Fazenda Pública, por ser obrigada ao regime constitucional de precatórios, não teria a opção de efetuar espontaneamente o pagamento de crédito dela exigido por decisão judicial transitada em julgado. A obrigação de pagamento de honorários sucumbenciais somente nasceria com a oposição de embargos à execução.

Contudo, os créditos definidos como de pequeno valor, não estando sujeitos ao regime de precatórios, podem ser pagos espontaneamente de modo que a cobrança forçada pelo credor seria resultante de resistência injustificada da Fazenda Pública, originando a causalidade ensejadora de honorários independentemente da apresentação de impugnação.

\section{FORMA DE PAGAMENTO DOS CRÉDITOS: PRECATÓRIOS OU RPV}

Com relação à forma de pagamento dos créditos, sejam eles originados de títulos judiciais ou extrajudiciais, não houve alteração no NCPC. O procedimento a ser adotado é o regime constitucional de precatórios (art. 100 da Constituição Federal) ou o procedimento da RPV (art. 87 do Ato das Disposições Constitucionais Transitórias - ADCT - e $\int 3^{\circ}$ do art. 100 da Constituição Federal), a depender do valor do crédito executado. Nesse sentido, uma vez deferido o pedido de cumprimento de sentença ou caso não seja apresentada impugnação pela Fazenda Pública, como se trata de valores a serem pagos pelas Fazendas Públicas federal, estadual e municipal, o pagamento será realizado por meio de precatório ou RPV.

Com efeito, a regra geral é que a execução contra a Fazenda não será feita mediante constrição, penhora ou expropriação de bens, mas por meio da expedição de precatório, que é o instrumento pelo qual o poder judiciário requisita o

5 NUNES, Jorge Amaury Maia; NÓBREGA, Guilherme Pupe. Processo e procedimento: notas sobre a execução contra a Fazenda Pública. 2016. Disponivel em: <http://www.migalhas.com.br/ProcessoeProcedimento/106,MI241130,11049-Notas+sobre+a+execucao+contra+a+Fazenda+Publica>. Acesso em: 5 out. 2016. 
pagamento do valor a que a Fazenda Pública tenha sido condenada em processo judicial. Segundo Lourenço, ${ }^{6}$

Existe todo um procedimento diferenciado apara a Fazenda Pública por uma série de razões, tais como a inalienabilidade dos bens públicos, a continuidade do serviço público e, ainda, a isonomia no pagamento que será feito, considerando que este se dará em grande parte por precatório.

O pagamento dos precatórios é regido pelo art. 100 da Constituição Federal, o qual prevê que devem ser pagos na estrita ordem cronológica de apresentação e à conta dos respectivos créditos.

Já o pagamento por meio de RPV está definido pelo art. 87 do ADCT. O $\ 3^{\circ}$ do art. 100 da Constituição Federal prevê que os créditos definidos em lei como de pequeno valor não se submetem ao regime dos precatórios. De acordo com o art. 535, $\int 3^{\circ}$, inciso II, do NCPC, o pagamento de obrigação de pequeno valor será realizado no prazo de dois meses contado da entrega da requisição, mediante depósito na agência de banco oficial mais próxima da residência do exequente.

No âmbito federal, a Lei n. 10.259/2001 (Lei dos Juizados Especiais Federais) estabelece o limite de 60 salários-mínimos para os pagamentos por meio de RPV. No âmbito estadual, o referido art. 87 do ADCT estabelece o limite de 40 salários-mínimos para a expedição de RPV em face da Fazenda Pública do estado e distrital federal, podendo tal limite ser alterado caso haja lei específica estabelecendo valor diverso. Por fim, a expedição de RPV em face da Fazenda Pública dos município está limitada a 30 salários-mínimos, caso também não haja lei municipal estabelecendo limite diverso.

\subsection{Inaplicabilidade da multa de 10\% à Fazenda Pública}

$\mathrm{O}$ art. 534, $₫ 2^{\circ}$, do NCPC é expresso ao afirmar que "a multa prevista no $₫ 1^{\circ}$ do art. 523 não se aplica à Fazenda Pública”. A multa em questão é a de 10\% pelo não pagamento espontâneo no prazo de 15 dias a contar da intimação da decisão condenatória. O racional para a não aplicação da multa em questão reside no fato de que a Fazenda Pública não poderia ser penalizada pela prática de um ato que não está sob o seu controle, já que está sujeita a um regime próprio - precatório ou RPV, conforme explicitado.

6 LOURENÇO, Haroldo. Manual de Direito Processual Civil. Rio de Janeiro: Forense, 2013. 
De acordo com Bueno, ${ }^{7}$

A Fazenda não é - e não pode ser, sem agressão ao art. 100 da CF - intimada para pagar (mas sim para impugnar, v. art. 535) e, portanto, não tem sentido sujeitá-la àquela multa, visando compeli-la à adoção de um comportamento que, desde o art. 100 da CF, lhe é vedado.

A jurisprudência há muito pacificou o seu entendimento acerca dessa questão ainda na égide do $\mathrm{CPC} / 73 .^{8}$

\subsection{Possibilidade de execução provisória da sentença}

$\mathrm{O}$ art. 534 do NCPC não condiciona o início do procedimento de cumprimento de sentença ao trânsito em julgado, possibilitando, portanto, o cumprimento provisório de sentença contra a Fazenda Pública, desde que respeitado o disposto nos art. 100 e seguintes da Constituição Federal e o art. $2^{\circ}-\mathrm{B}$ da Lei n. 9.494, de 10 de setembro de 1997.

De fato, ainda que o trânsito em julgado não seja obrigatório para iniciar o procedimento de cumprimento de sentença, este permanece imprescindível no momento da expedição do precatório. Nesse sentido são os seguintes comentários:?

Primeiramente observa-se que o caput do art. 534 não parece condicionar a admissibilidade do pedido do credor e, portanto, o início do procedimento de cumprimento de sentença ao trânsito em julgado. Logo, poder-se-ia admitir a possibilidade de cumprimento provisório de sentença contra a Fazenda Pública.

Todavia, necessário que tal regra esteja em consonância ao disposto no art. 100 da $\mathrm{CF} / 88$, o qual, em seu parágrafo $5^{\circ}$ impõe que a inclusão no orçamento da entidade devedora é obrigatória quanto às sentenças transitadas em julgado.

7 BUENO, Cassio Scarpinella. Novo Código de Processo Civil anotado. São Paulo: Saraiva, 2015. p. 364-365.

8 Agravo de Instrumento n. 70051834968-RS, Rel. Laís Ethel Corrêa Pias, julgado em: 14 maio 2013.

9 WAMBIER, Teresa Arruda Alvim; DIDIER JR., Fredie; TALAMINI, Eduardo; DANTAS, Bruno. Breves comentários ao Novo Código de Processo Civil, de acordo com as alterações da Lei nº 13.256/2016. 2. ed. São Paulo: Revista dos Tribunais, 2016. p. 1464. 
Dessa forma, ainda que seja possível a realização de todos os atos procedimentais que antecedem a expedição da ordem de pagamento (precatório ou $\mathrm{RPV}$ ), este somente será concretizado após o trânsito em julgado da sentença condenatória.

\section{CONCLUSÃO}

Diante de todo o exposto, constata-se que o procedimento de execução contra a Fazenda Pública foi substancialmente aprimorado pelo NCPC se comparado com o procedimento previsto no art. 730 e seguintes do CPC/73.

O CPC/73 previa um procedimento único para a execução contra a Fazenda Pública, que contemplava tanto os títulos judiciais quanto os extrajudiciais. O NCPC, contudo, segregou em dois os ritos de execução de créditos contra a Fazenda Pública com base na natureza dos títulos a serem executados: cumprimento de sentença quando se tratar de título executivo judicial (art. 534 e 535) e execução contra a Fazenda Pública quando o título for extrajudicial (art. 910).

Na modalidade de cumprimento de sentença, não será mais instaurado um processo autônomo de execução, com a citação da Fazenda Pública para a oposição de embargos, mas ocorrerá sua intimação para apresentar impugnação. $\mathrm{O}$ procedimento será instaurado nos próprios autos, como uma fase subsequente ao processo de conhecimento.

Com relação à forma de pagamento dos créditos, sejam eles originados de títulos judiciais ou extrajudiciais, não houve alteração no NCPC. Com efeito, permanece a necessidade de trânsito em julgado para a expedição do precatório, ou da RPV, conforme o disposto no art. 100 da Constituição Federal e no art. 87 do ADCT. Contudo, é possível o cumprimento provisório da sentença, ou seja, a adoção de todos os procedimentos necessários para a expedição da ordem de pagamento, mas para que esta seja efetivada deve haver obrigatoriamente o trânsito em julgado da sentença condenatória.

Ademais, o NCPC previu de forma expressa a inaplicabilidade da multa de $10 \%$ pelo não pagamento espontâneo no prazo de 15 dias a contar da intimação da decisão condenatória (art. 534, \20). Embora tal entendimento já estivesse pacificado na doutrina e na jurisprudência, o NCPC deixou claro que a Fazenda Pública não poderia ser penalizada pela prática de um ato que não está sob o seu controle, já que está sujeita a um regime próprio - precatório ou RPV.

Cumpre ressaltar ainda que, caso a execução não seja impugnada ou as alegações da Fazenda Pública sejam rejeitadas, será determinada a expedição de 
precatório ou RPV, a depender do valor do crédito, sendo também permitido o cumprimento parcial da sentença no que se refere à parcela incontroversa do crédito (rejeitada ou não impugnada).

Em suma, o NCPC introduziu alterações importantes e positivas para a execução de títulos em face da Fazenda Pública. A segregação do procedimento de execução contra a Fazenda Pública em dois facilitou e tornou mais célere o recebimento dos valores, especialmente na modalidade de cumprimento de sentença, prestigiando a duração razoável do processo sem afetar o regime especial que é aplicável à Fazenda Pública (regime constitucional dos precatórios ou RPV). 